\title{
DA UTILIZAÇÃO DAS PROVAS ILÍCITAS NO PROCESSO PENAL
}

\author{
Beatriz Rezende Pereira Souza; Eduardo Buzetti Eustachio Bezerro, Fábio Ferreira Morong \\ Universidade do Oeste Paulista - UNOESTE, Presidente Prudente, SP. E-mail: beatriz rezende97@hotmail.com
}

\section{RESUMO}

O presente artigo tem por objetivo, discutir o embate existente entre a vedação da utilização das provas ilícitas, inicialmente descrita no art. 5ㅇ, LVI da Carta Magna, também através do art.157, caput, do Código de Processo Penal, e entre o princípio da proporcionalidade, que embora haja sua existência e defesas em massa quanto sua utilização, ainda há controvérsias e resistência em sua aplicação no atual ordenamento. Ademais, o estudo visa o entendimento da possibilidade e meios de aplicação de tal princípio, a fim de que haja uma flexibilização da norma para com a realidade social. O método utilizado foi o indutivo legal, baseado na interpretação da Constituição Federal, legislação, pesquisa bibliográfica fundamentada em leitura de literatura jurídica e artigo científico. Conclui-se que a utilização do princípio da proporcionalidade, em consonância com a atual realidade social, propiciará uma busca justa e eficaz da verdade real, havendo equidade nas conclusões processuais.

Palavras-chave: Lei. Flexibilização. Princípio. Proporcionalidade. Provas. llícitude. Mitigação. Justiça.

\section{USE OF UNLAWFUL EVIDENCE IN CRIMINAL PROCEEDINGS}

\begin{abstract}
The purpose of this article is to discuss the existing conflict between the prohibition of the use of illicit evidence, initially described in art. 5, LVI of the Magna Carta and also through art.157, caput, of the Code of Criminal Procedure, and between the principle of proportionality, that although there is its existence and mass defenses as to its use, there is still controversy and resistance in its application in the current planning. In addition, the study aims at understanding the possibility and means of applying such a principle, so that there is a relaxation of the norm to the social reality. The method used was the legal inductive, based on the interpretation of the Federal Constitution, legislation, bibliographic research based on reading of legal literature and scientific article. It is concluded that the use of the principle of proportionality in accordance with the current social reality, will allow a fair and effective search of the real truth, with fairness in the procedural conclusions.
\end{abstract}

Keywords: Law. Flexibilization. Principle. Proportionality. Evidences. Illicit. Mitigation. Justice. 


\section{INTRODUÇÃO}

Nos termos do art.5ํ. LVI, da Carta Magna, será inadmissível a introdução de provas obtidas através de meios ilícitos no processo. Seguindo a mesma objetividade, o art. 157, caput, do Código de Processo Penal mediante redação dada pela lei no 11.690/08, reproduziu a mesma expressão escrita. Com isso, temos a presença de uma unidade, não permitindo a adequação da norma através do principio da proporcionalidade.

Tais normas advindas da jurisprudência norte-americana, fez com que a doutrina e a jurisprudência brasileira se posicionassem no sentido de que em circunstância alguma deverão ser aceitas provas ilícitas no processo penal, mesmo em se tratando de fato relevante por ela apurada. Não se trata somente de uma restrição constitucional, mas sim, da proteção do cidadão diante do "ius puniendi" pertencente ao Estado, focando também, na segurança jurídica a ser preservada.

Embora atualmente a doutrina adote em massa tal entendimento em virtude da unidade do ordenamento jurídico, existem alguns julgados e julgadores que conferem certa flexibilidade quanto á vedação constitucional, no intuito de impedir que ocorram deturpações que seriam causadas em casos singulares, além disso, esse novo prisma permite que nesses casos excepcionais intente-se a proteção de valores mais significativos do que a violação legal na colheita de provas.

O objetivo do presente artigo, é buscar uma maior flexibilização da norma diante da discussão entre o respeito das normas para a preservação da segurança jurídica e a adequação da norma ao caso concreto para salvaguardar um bem maior em relação a um bem menor, através da ponderação, fazendo do ordenamento um instrumento para chegar-se à verdade real.

\section{METODOLOGIA}

O presente trabalho teve por objetivo apresentar o panorama das provas ilícitas e ilegítimas no Brasil, sua condensação no sistema constitucional e infraconstitucional, além de permitir analisar sua aplicabilidade em favor da sociedade, por meio de pesquisa bibliográfica fundamentada em leitura de literatura jurídica e legislações, artigo científico jurídico, a partir da construção do método de abordagem indutivo.

\section{DA PROVA ILÍCITA E ILEGÍTIMA}

De acordo com o art.5ำ LVI, da CF "São inadmissíveis, no processo, as provas obtidas por meios ilícitos" (BRASIL, 1988).

As provas tornam-se ilícitas quando em sua obtenção são violados princípios constitucionais ou preceitos legais de natureza material. Tais ilícitos constituem-se de variados modelos de lesões aos preceitos múltiplos do ordenamento jurídico.

Nesse sentido, alguns exemplos são dados por Mougenot (2016, p.420) como a confissão do acusado obtida mediante tortura, violando o direito á incolumidade física (art.5으, III, da CF) e o principio da dignidade humana (art.1으, III, da CF); assim como a busca e apreensão domiciliar realizada sem autorização judicial ou durante a noite (art.5으, XI, da CF); a interceptação telefônica efetivada sem permissão judicial (art.5ํㅗ XII, CF), entre outras. 
Entretanto, a prova ilegítima tem como característica a infração da norma processual em relação á produção de provas. Como por exemplo, quando houver vestígios da uma infração e o laudo do exame de corpo e delito, direto ou indiretamente, for suprido pela confissão do acusado (Mougenot, 2016).

Em tese, a prova ilegítima causaria a nulidade da prova, não a tornando ilícita. Porém, com a nova redação dada pela lei no 11.690/08 ao art.157, caput, do CPP, ao referir-se as normas constitucionais sendo violadas, o legislador agregou a mesma eficácia ás provas ilícitas e ilegítimas, não havendo mais distinção entre elas, sendo a violação das normas constitucionais uma violação ao direito constitucional material e processual (BRASIL, 2008).

\section{DA TEORIA DOS FRUTOS DA ÁRVORE ENVENENADA}

Derivada da teoria norte-americana fruits of the poisonous tre $e^{1}$, tem-se como lógica a aplicação do princípio da inadmissibilidade das provas ilícitas. Por isso, deverão ser expurgadas do processo as provas ilícitas, assim como as demais que forem correspondentes a aquelas, pois estas restarão contaminadas.

Tem-se então que:

O nosso ordenamento acampou a doutrina dos frutos da árvore envenenada, segundo o qual não se admitirá no processo as provas ilícitas, isto é, contaminadas por vicio de ilicitude ou ilegitimidade, sendo certo que todas as demais delas decorrentes também estarão contaminadas com tal vicio e deverão ser expurgadas do processo. (HC 204.778/SP 6. a T., rel. Og Fernandes, j. 04.10.2012, v.u.).

Portanto, aplicar-se-á tal regra em se tratando de provas decorrentes, ou seja, aquela derivada da primeira prova.

\section{DA POSSIBILIDADE DO USO DOS FRUTOS DA ÁRVORE ENVENENADA}

O parágrafo 10 do art.157 do CPP preceituou que "são também inadmissíveis as provas derivadas das ilícitas, salvo quando não evidenciado o nexo de causalidade entre umas $e$ outras, ou quando as derivadas puderem ser obtidas por uma fonte independente das primeiras". Há, portanto, a "mitigação" do principio da inadmissibilidade das provas ilícitas. (BRASIL, 1941).

Na realidade, a norma não aduz realmente as provas ilícitas por derivação. Na primeira hipótese temos a exceção da falta de evidências do nexo de causalidade entre ambas (derivada e ilícita), sendo o nexo de causalidade nas palavras de Nucci (2015, p.53), um liame vinculador entre as duas coisas, constituindo-se através da causa e efeito. Portanto, se determinada coisa é considerada ilícita, existindo nexo de causalidade, haverá derivação, e inexistindo nexo, deixa de existir, igualmente, a derivação.

Já em relação ás fontes independentes, são aquelas que durante a investigação ou ao longo de toda a instrução criminal, as provas podem ser buscadas em variadas fontes, podendo haver a coincidência do encontro de trilhas, podendo a mesma prova ser encontrada por duas ou mais pessoas envolvidas nessa busca ao mesmo tempo, porém, faz-se necessário que as fontes sejam variadas, assim, uma torna-se independente á outra.

Assim, nos termos de Pacelli (2016, p. 366):

\footnotetext{
${ }^{1}$ Teoria dos frutos da árvore envenenada ou dos frutos da árvore venenosa.
} 
Em primeiro lugar, pode ocorrer que a prova posteriormente obtida já estivesse, desde o inicio, ao alcance das diligências mais frequentemente realizadas pelos agentes da persecução penal. Pode ocorrer, de fato, que seja possível concluir que o conhecimento da existência de tais provas se daria sem o auxilio da informação ilicitamente obtida.

Por fim, o parágrafo 2 을 do art.157 do CPP expõe que "considera-se fonte independente aquela que por si só, seguindo os trâmites típicos e de praxe, próprios da investigação ou instrução criminal, seria capaz de conduzir ao fato objeto da prova". .(BRASIL, 1941).

Desnecessária foi á conceituação da fonte independente, porém, o cuidado do legislador tem a finalidade de evitar qualquer desgaste de interpretações controversas, findando hipóteses de perda de provas importantes somente pelo fato de terem tido contato com provas consideradas ilícitas.

\section{DA AXIOLOGIA DAS PROVAS ILÍCITAS}

Neste novo cenário, tem-se centralizada as possíveis valorações a serem dadas ás provas consideradas ilícitas. Esta busca pelo equilíbrio entre o cidadão e as garantias fundamentais para a realização de um processo penal eficaz e justo, faz com que os tribunais pátrios, utilizem a mitigação da vedação existente ás provas ilícitas, admitindo a eficácia desta, desde que tal prova não seja adotada como elemento único de decisão, assim como seu conteúdo não corrobore nos demais elementos probatórios existentes no processo.

Porém, vale dizer, que em nosso Estado Democrático de Direito não existem tabelas de valores a serem plicadas de maneira genérica ou abstrata, de forma que seja estabelecida qual prova será preponderante ás outras. O fato é que ocorrem conflitos constantes entre princípios constitucionais e demais direitos igualmente protegidos, como, a vida, a segurança, a liberdade, a igualde e etc. (MOUGENOT, 2016).

Nesta hipótese, razoável seria a aplicação do "princípio da proporcionalidade", servindo como uma balança entre os princípios para que com sua razoabilidade sopese o fato concreto e os princípios constitucionais, mitigando a restrição da utilização das provas ilícitas, e utilizando-as em corroboração ao processo. Entretanto, o uso desse princípio só tem sido permitido quando a produção da prova ilícita estiver ligada á defesa do réu, aplicando o princípio "in dubio pro reo" como escopo para a aplicação das provas ilícitas obtidas.

Contudo, ainda há a discussão referente ao não uso das provas ilícitas em se tratando da acusação. O "pro societate", que é aquele em que na duvida, favorece-se a sociedade, não aceito na atual legislação, entretanto, há momentos em que as duvidas fundam-se na inexistência de provas materiais, embora seja sabido que as chances do crime ter sido cometido sejam altíssimas, ou a vítima, por se encontrar em uma situação vulnerável e inferior, possui o poder de acusação reduzido e duvidoso.

Nesse sentido, segundo Moraes (apud SILVA, 2011):

Essa atenuação prevê, com base no Princípio da Proporcionalidade, hipóteses em que as provas ilícitas, em caráter excepcional e em casos extremamente graves, poderão ser utilizadas, pois nenhuma liberdade pública é absoluta, havendo possibilidade, em casos delicados, em que se percebe que o direito tutelado é mais importante que o direito à intimidade, segredo, liberdade de comunicação, por exemplo, devendo permitir-se sua utilização. 
Com isso, vê-se que há valores mais relevantes a serem considerados do que aqueles que foram violados no momento da colheita da prova. Pode-se dizer que, trata-se de uma afronta ao princípio do livre convencimento do juiz no momento em que Estado minimiza o poder que fora a ele investido quando o magistrado é obrigado a desconsiderar a realidade por ele observada.

Em entendimentos mais abrangentes, seria até mesmo possível que o juiz lançasse mão do princípio da proporcionalidade, admitindo a prova ilícita na medida em que o caso concreto apresente um indeclinável conflito de valores, fazendo imprescindível sua admissão para resguardar um bem maior em relação a um menor.

Observe a afirmação dada pelo Min. Celso de Mello no julgamento do RE $\mathrm{n}$ 251.445/GO (DJU 3.8.2000):

PROVA ILÍCITA. MATERIAL FOTOGRÁFICO QUE COMPROVARIA A PRÁTICA DELITUOSA (LEI № 8.069/90,ART. 241). FOTOS QUE FORAM FURTADAS DO CONSULTÓRIO PROFISSIONAL DO RÉU E QUE, ENTREGUES À POLÍCIA PELO AUTOR DO FURTO, FORAM UTILIZADAS CONTRA O ACUSADO, PARA INCRIMINÁ-LO.INADMISSIBILIDADE (CF, ART. 50,LVI).- A cláusula constitucional do due process of law encontra, no dogma da inadmissibilidade processual das provas ilícitas, uma de suas mais expressivas projeções concretizadoras, pois o réu tem o direito de não ser denunciado, de não ser processado e de não ser condenado com apoio em elementos probatórios obtidos ou produzidos de forma incompatível com os limites ético-jurídicos que restringem a atuação do Estado em sede de persecução penal. (BRASIL, 2000)

O fato apresentado trata-se da inadmissibilidade de provas ilícitas em face do suposto autor do crime, que estaria envolvido em crimes de natureza sexual contra menores. Com esse posicionamento, tem-se uma grande perda da utilização do princípio da proporcionalidade em um caso de caráter gravíssimo que ainda gera grande impunidade de agentes no Brasil.

Aderindo o raciocínio de Pacelli (2016, p. 378), tal vedação das provas ilícitas não cumpriu nenhum de seus propósitos finalísticos, tendo em vista que tal garantia visa á restrição do excesso na produção de provas pelo Estado, já que a prova não havia sido produzida por este, mas sim, por um particular. Porém, restou impune aquele que atentou contra vítimas frágeis, que não possuem meios de defesas equivalentes aos do autor, inexistindo por fim, equidade de direitos.

Portanto, não é correto que a presunção de inocência aplicada ao réu através dos direitos humanos, crie o direito de garantir a impunidade de seus crimes, responsabilizando o Estado, mas não aquele que comprovadamente cometeu o ato ilícito.

\section{CONCLUSÃO}

Desta forma, através do presente artigo, nota-se que as provas possuem um papel fundamental na decisão do magistrado, assim como, na manutenção da segurança jurídica, não podendo ser produzida e nem aplicada de maneira arbitrária. Porém, o direito constitucional aplicado às provas não é absoluto, demonstrando limitações quando ocorrem conflitos entre a norma constitucional e os demais direitos tutelados. Com isso, restou demonstrada a necessidade da flexibilização das normas em virtude das necessidades sociais.

Assim sendo, o Estado deve buscar a verdade, livrando-se de distorções, no que tange tais limitações. Acima de tudo, o poder Estatal deve conservar a integridade social, fazendo da norma um instrumento de aplicabilidade justa da tutela jurisdicional. No mais, tais amarras devem ser soltas quando existirem deficiências a serem sanadas através de meios alternativos, 
que evidentemente, preservará o bem maior existente nesta relação, a justiça. Portanto, conclui-se que a utilização do princípio da proporcionalidade em consonância com a atual realidade social, propiciará uma busca justa e eficaz da verdade real, havendo equidade nas conclusões processuais.

\section{REFERÊNCIAS}

ANGHER, Anne Joyce (Org.). Vade mecum acadêmico de direito. 22.ed. São Paulo: Rideel, 2016.

BRASIL. Constituição. (1988). Constituição da República Federativa do Brasil. Brasília. Senado federal, 2016.

BRASIL. Decreto-lei no 3.689, de 3 de outubro de 1941 . Disponível em: <http://www.planalto.gov.br/ccivil_03/decreto-lei/Del3689Compilado.htm>. Acesso em 08 ago. 2018.

BRASIL. Superior Tribunal de Justiça - HC: 204778 SP 2011/0091670-9, Relator: Ministro OG FERNANDES, Data de Julgamento: 04/10/2012, T6 - SEXTA TURMA, Data de Publicação: DJe 29/11/2012). Disponível em: <https://stj.jusbrasil.com.br/jurisprudencia/22888033/habeascorpus-hc-204778-sp-2011-0091670-9-stj/inteiro-teor-22888034?ref=juris-tabs > Acesso em: 03. Ago. 2018.

BRASIL. Supremo Tribunal Federal - RE: 251445 GO, Relator: Min. CELSO DE MELLO. Data de Julgamento: 21/06/2000, Data de Publicação: DJ 03/08/2000 PP-00068. Disponível em: < https://stf.jusbrasil.com.br/jurisprudencia/14825705/recurso-extraordinario-re-251445-gostf?ref=serp> Acesso em: 05. Ago. 2018.

MOUGENOT, Edilson. Curso de Processo penal. 11.ed. São Paulo: Editora Saraiva, 2016.

NUCCI, Guilherme de Souza. Provas no Processo Penal. 4. ed. Rio de Janeiro: Gen, 2015.

PACELLI, Eugênio. Curso de Processo Penal. 20. ed. São Paulo: Atlas, 2016. 
SILVA, Ana Patrícia G. A prova ilícita no processo penal. Disponível em: <https://www.direitonet.com.br/artigos/exibir/6150/A-prova-ilicita-no-processo-penal> Acesso em: 03 Ago. 2018. 